\title{
Underestimation of arterial oxygen tension by transcutaneous electrode with increasing age in infants
}

\author{
P A HAMILTON, M D WHITEHEAD, AND E O R REYNOLDS \\ Department of Paediatrics, University College London School of Medicine, London
}

SUMMARY To investigate the effect of increasing gestational and postnatal age on the relation between transcutaneous oxygen tension $\left(\mathrm{tcPO}_{2}\right)$ and arterial oxygen tension $\left(\mathrm{PaO}_{2}\right) 160$ simultaneous measurements of $\mathrm{tcPO}_{2}$ and $\mathrm{PaO}_{2}$ tensions were made on 42 infants born at 24-41 weeks' gestation and aged 0-32 weeks from birth. Irrespective of gestational age a progressive fall in the tcPO $: \mathrm{PaO}_{2}$ ratio with increasing postnatal age was found. At all postnatal ages tcPO $: \mathrm{PaO}_{2}$ tended to be lower in the more mature infants.

Transcutaneous oxygen $(\mathrm{tcPO})$ electrodes have been shown to estimate accurately arterial oxygen $\left(\mathrm{PaO}_{2}\right)$ in infants in the first week of life, provided that the infant is not severely ill and that perfusion of the skin is adequate. ${ }^{1-3}$ Few studies of older infants have been performed, but there is some evidence to suggest that $\mathrm{tcPO}_{2}$ electrodes underestimate $\mathrm{PaO}_{2}$ in those with bronchopulmonary dysplasia. ${ }^{4} \mathrm{We}$ investigated whether there were any systematic changes in the relation between $\mathrm{tcPO}_{2}$ and $\mathrm{PaO}_{2}$ with increasing gestational and postnatal age.

\section{Methods}

Infants studied. Simultaneous measurements of tc $\mathrm{PO}_{2}$ and $\mathrm{PaO}_{2}$ were made on 160 occasions on 42 infants being treated in the Neonatal Unit of University College Hospital. The median number of observations in each infant was three (range 1-17). The infants were born at 24-41 weeks' gestation, weighing 560-4075 g; 16 were girls and 26 were boys. The Table gives the principal diagnoses.

Thirty three infants survived and nine died. Ninety two observations were made on infants who were breathing spontaneously, eight on infants being treated by continuous positive airway pressure, and 60 on those who were mechanically ventilated. The median fractional inspired oxygen tension $\left(\mathrm{FiO}_{2}\right)$ when observations were made was 0.35 (range $0 \cdot 21-1 \cdot 00, n=151$ ); on nine occasions when low-flow oxygen was being administered through nasal catheters $\mathrm{FiO}_{2}$ was not known.
Table Principal diagnoses in the 42 infants (some infants had more than one diagnosis)

\begin{tabular}{lll}
\hline Diagnosis & No of infants \\
\hline Hyaline membrane disease & 17 \\
Chronic lung disease & 15 \\
Transient tachypnoea & 6 \\
Recurrent apnoea & 5 \\
Pneumonia & 3 \\
Birth asphyxia & 2 \\
Pulmonary interstitial emphysema & 2 \\
Small for gestational age & 2 \\
Meconium aspiration & 1 \\
Duodenal atresia & 1 \\
lleal perforation & 1 \\
Hirschsprung's disease & 1 \\
Subglottic stenosis & 1 \\
Total & 57 \\
\hline
\end{tabular}

Procedure. Whenever possible, observations were made on the first day of life and then at weekly 3 intervals until the infant was discharged or blood gas analysis was no longer clinically warranted. Observations were omitted if the infants were $\frac{7}{0}$ extremely ill or hypotensive, the peripheral perfusion was poor, as judged visually or by a rectal-toe $\tilde{N}$ temperature difference of $6^{\circ} \mathrm{C}$ or more, or the arterial packed cell volume was less than $30 \%$, as $\mathrm{N}$ these circumstances may cause underestimation of $\omega$ $\mathrm{PaO}_{2}$ by $\mathrm{tcPO}_{2}{ }^{3}$

Measurement of tcPO $\mathbf{2}_{2}$. A Dräger Transoxode electrode (Drägerwerk, Lubeck, W Germany) was used $\stackrel{+}{+}$ for measurement of tcPO $\mathrm{PO}_{2}$. The membrane material, $\frac{\mathrm{T}}{\mathrm{T}}$ $25 \mu \mathrm{m}$ thick Teflon, and the electrolyte were $\underset{\mathbb{D}}{\circ}$ 
supplied by the manufacturer. The electrode was heated to $44^{\circ} \mathrm{C}$ and calibrated with two certified dry gas mixtures containing $0 \%$ oxygen (with $10 \%$ carbon dioxide and nitrogen) and $12 \%$ oxygen (with $5 \%$ carbon dioxide and nitrogen). An appropriate allowance for barometric pressure was made. The electrode was attached with an adhesive ring to an area of skin supplied by the artery chosen for measurement of $\mathrm{PaO}_{2}$. A continuous record of $\mathrm{tcPO}_{2}$ was displayed on a chart recorder.

Measurement of $\mathrm{PaO}_{2}$. Whenever possible, samples for measurement of $\mathrm{PaO}_{2}$ were taken from catheters sited in the umbilical artery $(n=19)$ or in peripheral arteries $(n=4)$. When no arterial catheter was available, the sample was obtained by direct puncture either of the right radial or brachial artery $(n=109)$ or of the left brachial or radial artery or a posterior tibial artery $(n=28)$. A 25 gauge 'butterfly' needle was used, with all but $5 \mathrm{~mm}$ of the attached plastic tubing removed. For collection of the sample $(0.2 \mathrm{ml})$, two $105 \mathrm{~mm}$ long, dry heparinised glass capillary tubes joined together by $5 \mathrm{~mm}$ of plastic tubing were used, with one free end connected to the needle. When the artery was punctured, blood rose freely and rapidly into the tubes. The tcPO $\mathrm{Palue}_{2}$ taken for comparison with $\mathrm{PaO}_{2}$ was recorded 40 seconds after the midpoint of the blood flow to allow for the response time of the tcPO $\mathrm{P}_{2}$ electrode. $\mathrm{PaO}_{2}$ was measured at $37^{\circ} \mathrm{C}$ using an Instrumentation Laboratories 1303 blood gas analyser, the accuracy of which had been checked with tonometered blood. Observations were discarded if the infant was more than minimally disturbed by the sampling procedure or the $\mathrm{tcPO}_{2}$ record showed any pronounced change. To verify that little change occurred the mean difference between the recorded tcPO value and $t c \mathrm{PO}_{2}$ value 10 seconds earlier was documented and found to be $0 \cdot 14(\mathrm{SD} 0.17) \mathrm{kPa}$; the difference 10 seconds later was $0 \cdot 15(0 \cdot 18) \mathrm{kPa}$. Mean (SD) rectal temperature at the time of sampling was $37.0(0.4)^{\circ} \mathrm{C}$.

\section{Results}

Figure 1 shows the relation between $\mathrm{tcPO}_{2}$ and $\mathrm{PaO}_{2}$ for all the pairs of observations made in the study. Data for infants less than 8 weeks old are given in Figure 1 (a) and for those aged 8 weeks or more in Figure 1 (b). The ratio tcPO $\mathrm{P}_{2}: \mathrm{PaO}_{2}$ was calculated for each pair of observations, and the relation between this ratio and increasing postnatal age is shown in Figure 2. In both Figures 1 and 2 different symbols are used to indicate data for infants born at less than 30 weeks' gestation or at 30 weeks and above. Figure 3 shows the relation

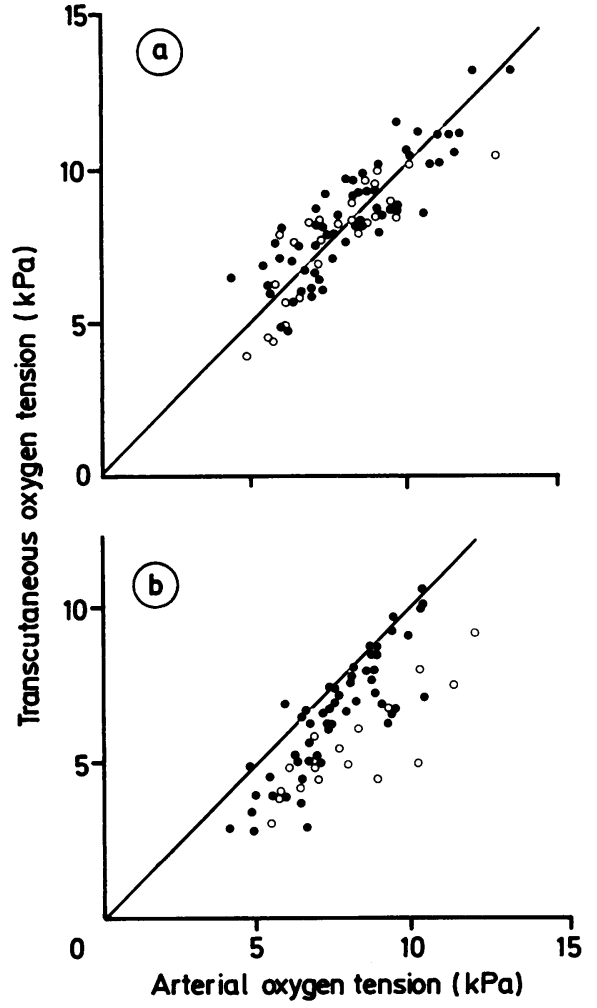

Fig. 1 Relation between transcutaneous oxygen tension $\left(t c \mathrm{PO}_{2}\right)$ and arterial oxygen tension $\left(\mathrm{PaO}_{2}\right)$ in 160 observations: (a) in infants of less than 8 weeks' postnatal age; $(b)$ in infants aged 8 weeks or more. = Data for infants born at less than 30 weeks' gestation; $\mathrm{O}=$ data for infants of 30 weeks' gestation or more. The lines of identity are shown.

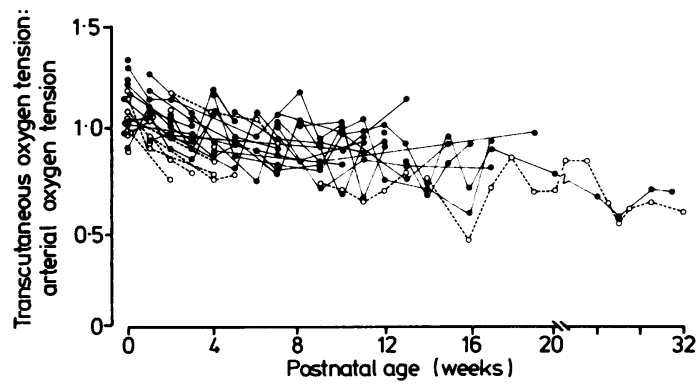

Fig. 2 Relation between transcutaneous oxygen tension:arterial oxygen tension ( $t c \mathrm{PO}_{2}: \mathrm{PaO}_{2}$ ) and postnatal age. = Data for infants born at less than 30 weeks' gestation; $\bigcirc=$ data for infants of 30 weeks' gestation or more. Data points from the same infant are joined. 


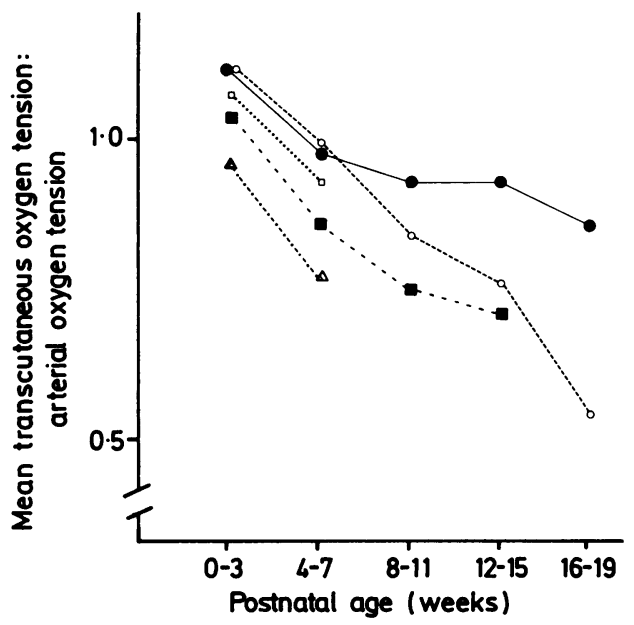

Fig. 3 Relation between transcutaneous oxygen tension:arterial oxygen tension ( $t c \mathrm{PO}_{2}: \mathrm{PaO}_{2}$ ) and postnatal age in infants of differing gestational ages at birth. = 24-27 Weeks, $\bigcirc=28-31$ weeks, $\square=32-35$ weeks, $\square=36-39$ weeks, $\triangle=40-43$ weeks. Each infant is represented no more than once at each postnatal age (the first value obtained), $n=1-11$ (mean=4). Only mean values are shown; the scatter of results was large (see text).

between $\mathrm{tcPO}_{2}: \mathrm{PaO}_{2}$ ratio and increasing postnatal age in infants grouped according to gestational age at birth.

\section{Discussion}

Inspection of Figure 1 (a) shows that the data points are clustered around the line of identity, and therefore that in infants less than 8 weeks old measurement of $\mathrm{tcPO}_{2}$ generally gave a good estimate of $\mathrm{PaO}_{2}$, irrespective of what gestation the baby had been born at. This is confirmed in Figure 2, which shows that the tc $\mathrm{PO}_{2}: \mathrm{PaO}_{2}$ ratio was usually close to 1.0 during the first eight weeks, but it can also be seen that the $\mathrm{tcPO}_{2}: \mathrm{PaO}_{2}$ ratio fell progressively with increasing postnatal age, leading to an underestimate of $\mathrm{PaO}_{2}$ by $\mathrm{tcPO}_{2}$ that is also apparent in Figure 1 (b). If all the data for infants aged 8 weeks and above are taken together, the mean value for $\mathrm{tcPO}_{2}: \mathrm{PaO}_{2}$ is 0.83 (SD $0 \cdot 15$ ) $(n=72)$, significantly lower than the mean value for infants aged less than 8 weeks of $1 \cdot 11(0 \cdot 11)(n=88$, $\mathrm{p}<0.001$ ). In infants who were more than 3 months old, tcPO $\mathrm{P}_{2}$ was almost always below 1.0 and often as low as 0.75 (Figure 2). Clearly, a fall in the $\mathrm{tcPO}_{2}$ : $\mathrm{PaO}_{2}$ ratio occurred with increasing postnatal age to a level where $\mathrm{PaO}_{2}$ was substantially underestimated. How much of this effect was due to differences in the skin associated with the different gestational ages of the infants at birth is difficult to assess. The data in Figures 1 (b) and 2 suggest that tc $\mathrm{PO}_{2}: \mathrm{PaO}_{2}$ was lower in infants born at 30 weeks or above than in less mature infants, and Figure 3 illustrates the trend towards lower values with increasing gestational age: however, no significant effect of gestational age at birth could be shown from these data.

The reasons for the fall in $\mathrm{tcPO}_{2}: \mathrm{PaO}_{2}$ with increasing postnatal age are not clear and are probably multifactorial. That the effect was not merely due to increasing maturation of the skin was shown by relating tc $\mathrm{PO}_{2}: \mathrm{PaO}_{2}$ to gestational age plus postnatal age: a much less clear relation emerged than with postnatal age alone (data not shown). Changes in the texture and thickness of the skin and in the capillary bed occur with increasing postnatal age, and permeability to oxygen decreases. ${ }^{5}$ All these factors could affect tc $\mathrm{PO}_{2}: \mathrm{PaO}_{2}$. A further possibility is that the fall in tc $\mathrm{PO}_{2}: \mathrm{PaO}_{2}$ may sometimes have been related to the presence of chronic lung disease. ${ }^{4}$ We could not, however, show such an effect, as six infants more than 8 weeks old had only minor pulmonary problems, yet their data were similar to those for the 13 infants whose lungs were more severely coms promised.

Our evidence that $t c \mathrm{PO}_{2}$ underestimates $\mathrm{PaO}_{2}$ progressively with increasing postnatal age has several implications. Firstly, infants may be nursed in an unnecessarily high ambient oxygen concentration. As the underestimate of $\mathrm{PaO}_{2}$ by $\mathrm{tcPO}_{2}$ only became pronounced in infants more than 3 months old, we doubt if the eyes of preterm infants would thereby be put at increased risk of retrolental fibroplasia, though this remains a remote possibility in the least mature infants. It is probable, though, that treatment with oxygen could be continued for longer than necessary, thus needlessly prolonging stay in hospital. This conclusion re-emphasises the importance of checking tcPO $\mathrm{P}_{2}$ values against $\mathrm{PaO}_{2}$ measured in carefully taken arterial samples. Our data also imply that the results of studies of older infants, where tc $\mathrm{PO}_{2}$ is regarded as giving an accurate estimate of $\mathrm{PaO}_{2}$, should be viewed with caution.

We thank Mr D T Delpy, Mr C Hemsley, and the staff of the Neonatal Unit for their help. This study was supported by the $\omega$ Medical Research Council.

\section{References}

1 Peabody J, Emery JR. Noninvasive monitoring of blood gases in $\mathscr{C}$ the newborn. Clin Perinatol 1985;12:147-60.

2 Pollitzer MJ, Whitehead MD, Reynolds EOR, Delpy D. Effect of electrode temperature and in vivo calibration on accuracy of

\section{,} (a)

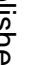


transcutaneous estimation of arterial oxygen tension in infants. Pediatrics 1980;65:515-22.

3 Versmold HT, Linderkamp O, Holzmann M, Strohhacker I, Riegel K. Transcutaneous monitoring of $\mathrm{PO}_{2}$ in newborn infants: where are the limits? Influence of blood pressure, blood volume, blood flow, viscosity and acid base status. In: Huch A. Huch R, Lucey JF, eds. Continuous transcutaneous blood gas monitoring. The National Foundation-March of Dimes. Birth defects: original article series, vol 15. New York: Alan Liss, 1979:285-95.

${ }^{4}$ Rome ES, Stork EK, Carlo WA, Martin RJ. Limitations of transcutaneous $\mathrm{PO}_{2}$ and $\mathrm{PCO}_{2}$ monitoring in infants with bronchopulmonary dysplasia. Pediatrics 1984;74:217-20.

5 Versmold HT, Holzmann M, Linderkamp O, Riegel KP. Skin oxygen permeability in premature infants. Pediatrics 1978;62:488-91.

Correspondence to Dr P A Hamilton, Department of Paediatrics, University College London School of Medicine, The Rayne Institute, University Street, London WC1E 6JJ.

Received 19 July 1985 